\title{
Problems of Solid Waste Management in Small and Medium Enterprises
}

\author{
Alie Wube Dametew \\ Department of Mechanical Engineering, and Research and technology Transfer Head, KIOT Wollo University, Dessie, Ethiopia \\ Email address: \\ wubealie@gmail.com \\ To cite this article: \\ Alie Wube Dametew. Problems of Solid Waste Management in Small and Medium Enterprises. International Journal of Environmental \\ Monitoring and Analysis. Vol. 3, No. 2, 2015, pp. 50-66. doi: 10.11648/j.ijema.20150302.14
}

\begin{abstract}
This study describes the problems of solid waste generation in small and medium scale enterprise. The analysis was conducted in Meserte Gabi metal and machine work enterprises using purposive sampling method with 16 sample sizes of this enterprise employer. Filed observation, unstructured interview, and questioners were instruments that use pre and post assessment tools for problems of solid waste management. The study explores the existing situation of the enterprises about solid waste management. The result shows that Solid waste issues were the major problems of Meserte Gabi metal and machine work enterprise. Findings show that waste prevention, recycling; collecting, and awareness, training and awareness are the major problems of the enterprises. After actions were done (conducting training, implementation of kaizen and capacity building) result predicts that, the impact of solid waste problem were changed and proper solid waste management systems were developed. The study highlights that it is essential that the government starts to recognize the mechanisms of supporting of enterprises in order to improve the overall solid waste management system in Dessise-Ethiopia. From the action obtained that conducting training, capacity building, resource utilization, and implementation of kaizen were mechanisms that developed solid management systems in the enterprises.
\end{abstract}

Keywords: Solid Waste, Reuse, Prevention, Kaizen, Waste Management

\section{Background and Introduction}

\subsection{Background}

In both developed and developing countries, the government is turning to small and medium scale industries and entrepreneurs, as a means of economic development and a veritable means of solving problems. Presently in Ethiopia, small and medium scale entrepreneurs assist in promoting the growth of the country's economy. Hence all the levels of government at different times have to promote policies which the growth and sustenance of small and medium scale entrepreneurs. But several wastes are observed in most small and medium scale entrepreneurs. These wastes are reducing the growth and maturity of enterprises and have impacts of sustainable developments. The purpose of waste management is used to have concentration for productivity, environmental problems and understand human responsibilities and role for environment, to care for attitude of participating in the solid waste management, and to develop mechanism and to solve the problem of enterprises. This project is prepared as a stimulating outcome of developing the method of solid waste management small and medium scale enterprises.

\subsection{Introduction}

Wastes are all forms of materials that are dangerous, toxic, reactive, explosive, flammable, organic or bacterial nature, are hazardous to the humankind and the environment as determined as waste. Waste represents the loss of both material and energy resources. Because excessive waste generation is a symptom of inefficient production processes, low durability of goods and unsustainable consumption patterns, waste quantities can be considered as an indicator of how efficiently society uses raw materials. Waste management is closely related to a number of issues such as urban lifestyle, resource consumption patterns, jobs and income levels, and other socio-economic and cultural factors.

Solid waste management is a mixture of human activities which tend to increase with rapid development, improved living standard and changing consumption of products. If solid waste is properly used, it can be a valuable resource, but if it is not effectively managed, it can result in serious adverse impacts on the growth and development of the 
enterprises. But Solid waste Management is the major challenge in small and medium scale enterprises in DessiseEthiopia. Solid waste management is therefore a critical component within the maturity and growth of the company. Hence this research aimed to develop the systems of solid waste management in small and medium scale enterprises.

\subsection{Statement of the Problem}

In Small and Medium scale metal and machine manufacturing enterprises are produce many products with different problems. One of the main problems is due to improper Waste management and lack of sustainable development. In this research the investigation was conducted to develop problems of solid waste management in Small and Medium scale metal and machine manufacturing enterprises. Also find out factors of waste formation and to develop waste minimization technique.

\subsection{Objectives}

\subsubsection{General Objectives}

The main objective of this study was to identify the major problems of Solid Waste and to develop Solid Waste Management systems in Small and Medium scale metal and machine manufacturing enterprises.

\subsubsection{The Specific Objective of This Study was}

- To identify the cause and main type of solid waste

- To assess the existing solid waste management systems of the enterprise.

- To apply the method of waste management for other enterprises in the Town.

- To develop solid Waste Management techniques

- Improve solid waste management for the enterprises

\subsection{Scope of Research}

The study is limited to problems of solid waste management of small and medium scale metal and machine work enterprises.

\subsection{Significance of the Study}

- The study contributes control the solid waste pollution effect of the enterprise in the town.

- indirectly to the implementation of change the economic development of the enterprise

- Contribute the building of environmental friendliness of the enterprise

- Contribute to resource utilization by re-use the waste.

\section{Literature Review}

\subsection{Introduction for Related Works}

A great deal of research has been conducted in order to reduce solid waste problems, which would optimize productivity of small enterprises by reducing the factors that improve the formation of solid waste in the enterprises. This research has played a major role in promoting waste reduction mechanisms in the small enterprises. This chapter tries to summarize some key background references and their contributions to the problem of solid waste. Dr Kalpana Sankar (2004) shows Key environmental problems Caused by poor sanitation, poor waste disposal and, these may lead to serious risks of environmental pollution and public health impacts

Christian Zurbrügg (2003) was develop successful innovative ideas and approaches have been implemented on different levels of the solid waste management system Seadon (2006) results revealed that solid waste was identified as the second most important problem of urban populations. Di Vita (2004). Shows that general awareness of site based waste management issues and the study recognizes the need for holistic approaches to be adopted across all sectors to improve solid waste problems. Jones (2007) to analyze the waste management practice, in particular of used in an industrial and to find out its critical features. Investigated possible links between the environmental management system and the improving and more correct administration of waste. Significant statistical associations improved administration of waste under multiple aspects was found. In the year 2007, China had the largest population in the world. The population of China is expected to grow, and due to the strong correlation between increases in population and increases in waste, waste in China is also expected to increase. Waste can be a by-product of a productive process or it can be an object that has reached the end of its life cycle and that no longer posses any value to the current user (Ferguson 1995). According to the International Solid Waste Association (ISWA) part of sustainability entails viewing waste as a resource (ISWA \& UNEP 2004).

If waste is viewed as a resource, resource management theory can be used to enlighten the underlying waste management theory. Zimmerman proposed: "Resources are not, they become; they are not static but expand and contract in response to human wants and actions... they evolve out of the triune interaction of nature, man, and culture, in which nature sets outer limits, but man and culture are largely responsible for the portion of physical totality that is made available for human use." (Zimmermann 1951). Applying principles to waste management, three assumptions can be inferred that contribute to how one can view the relationship between waste and resources. Waste is a subjective matter relative to humans, and fundamentally, it is anthropocentric. A plastic bag is not a resource or waste in itself: it depends on a human's ascription of value to it.

Secondly, the relationship between humans and waste is shaped by the interaction between humans, nature, and culture: that is, economics, process and technology. Processes such as recycling change the availability of plastics, metals, and paper in absolute terms. Finally, the definition of waste and resource expands and contracts in response to human want and action. Thus, if there were shortages in virgin products, then the value of the recycled products would likely increase and there would be more demand for recycled 
products .In many cases, value can be added and some utility can be restored to the waste, either through process or through a new type of usage (McDougall et al. 1995.The industrial ecology paradigm uses the practice of loop closing and industrial symbiosis to increase resource productivity and reduce waste (Ehrenfeld and Gertler 1997). According to Germany (Emscher Park) (Gibbs, 2003), and most recently China (Guitang Group sugar industrial cluster, and Nan hai National Eco-Industrial Park in Guangdong), These parks attempt to stimulate the symbiotic relationship between industries, where the waste produced by one industry is used as productive inputs into other industries.

(Maclaren 2005) synthesizes the literature on waste management systems in developing countries, she presents two approaches which describe preferred objectives of waste management systems The first approach she proposes is similar to applying the waste management hierarchy of developed countries. The developing country waste management hierarchy begins with waste prevention, toxicity reduction, reuse, recycling and composting, incineration, and disposal of any remaining wastes, ideally with energy recovery systems. The unique feature is toxicity reduction, which may be a paramount concern in developing countries. The second approach recognizes the pragmatic reality of the situation of waste management in many developing countries that $30-60 \%$ of waste is not collected. According to a Survey done by Nepal's central Bureau of Statistics (CBS), most Urban residents consider solid waste management as the most important environmental problem in urban areas of Nepal.

According to the data provided by the Municipality and the field survey conducted in May 2008, the average per capita household waste generation rate is $0.30 \mathrm{~kg} / \mathrm{capita} /$ day and the total daily waste generation is 25 tons. Vivian W. Y. Tam (2009) conducted that necessary to recycle concrete waste to preserve landfill areas. To reduce the amount of construction waste generated from sites, coordination among all those involved in the design and construction processes is essential. (Zurbrugg 2006) point out that there are both shortterm and long-term objectives of waste management's. The short-term objectives are waste collection and disposal; while the longer-term objectives are waste reduction and recycling.

Gloria Elizabeth Ichim (2007) identified seven necessary key factors that if not given sufficient attention could potentially expose the successful implementation and operation of composting: governmental support must be present, funds must be made available since operating cost of the waste management system will increase, best practices for composting must be established, training for waste workers must be provided, a market (or end use) for the final product must be established.

\subsection{The Relationship Between Climate Change and Solid Waste}

Prof. R. Rameezdeen (June 2010) The Earth's atmosphere contains many types of gases, including those known as "greenhouse gases," which hold in the sun's warmth.
Scientists call this naturally occurring phenomenon the "greenhouse effect." Greenhouse gases help regulate global temperatures. Certain human activities such as burning fossil fuels and dumping solid waste, however, produce additional greenhouse gases and upset the natural balance by raising global temperatures. Even before a material or product becomes solid waste, it goes through a long cycle that involves removing and processing raw materials, manufacturing the product, transporting the materials and products to markets, and using energy to operate the product.

The cause of a particular problem is due to improper managed hazardous waste disposal sites. Ethiopian government to develop solid waste management systems to reduce their problems. Despite the fact that controlling the effects of solid waste is under problems thus to solve such problem identification of the problem is developed using research is the beast method. Hence, the key research question addressed in this study is:

- Are problems of solid waste properly and effectively manage in Small and Medium scale metal and machine manufacturing enterprises?

- Is there any change of solid waste management from the past to the existing?

- What are the problems that delay waste management of Small and Medium scale metal and machine manufacturing enterprises?

\section{Methodology of the Study}

\subsection{Introduction}

This research the method of solid waste management systems was developed in Small and medium scale enterprise. Pre and post assessment was used to determine the change of improvements. The study was done through seven month with duration purposive was s done 16workers of In Small and medium scale enterprise. The researcher used descriptive method of research to study the specified problem.

\subsection{Sample Size and Sampling Procedure}

Since the researcher's intention was to identify a single problem and its solution in In Small and medium scale enterprise with 1manager and 15 enterprise employees, purposive sampling method was used. And the researcher also used only one enterprise considering the time and monetary problems to include more enterprises.

\subsection{Source of Data}

The main sources of data for this research were 1manager and 15 employees of In Small and medium scale enterprise. There were five female and ten meal employers a total of about 16 participants, in order to gather the necessary data required to conduct this study.

\subsection{Instruments and Data Collection Method}

In this study data was collected by different methods like 
field observations, questionnaires and interviews are presented.

\subsection{Data Analysis Method}

The collected data were analyzed and presented through
Pareto charts, tables and Fish bone diagrams. Finally, the analyzed data are interpreted, discussed and the findings were put in summary form.

\subsection{Procedure}

Table 3.1. Action plane

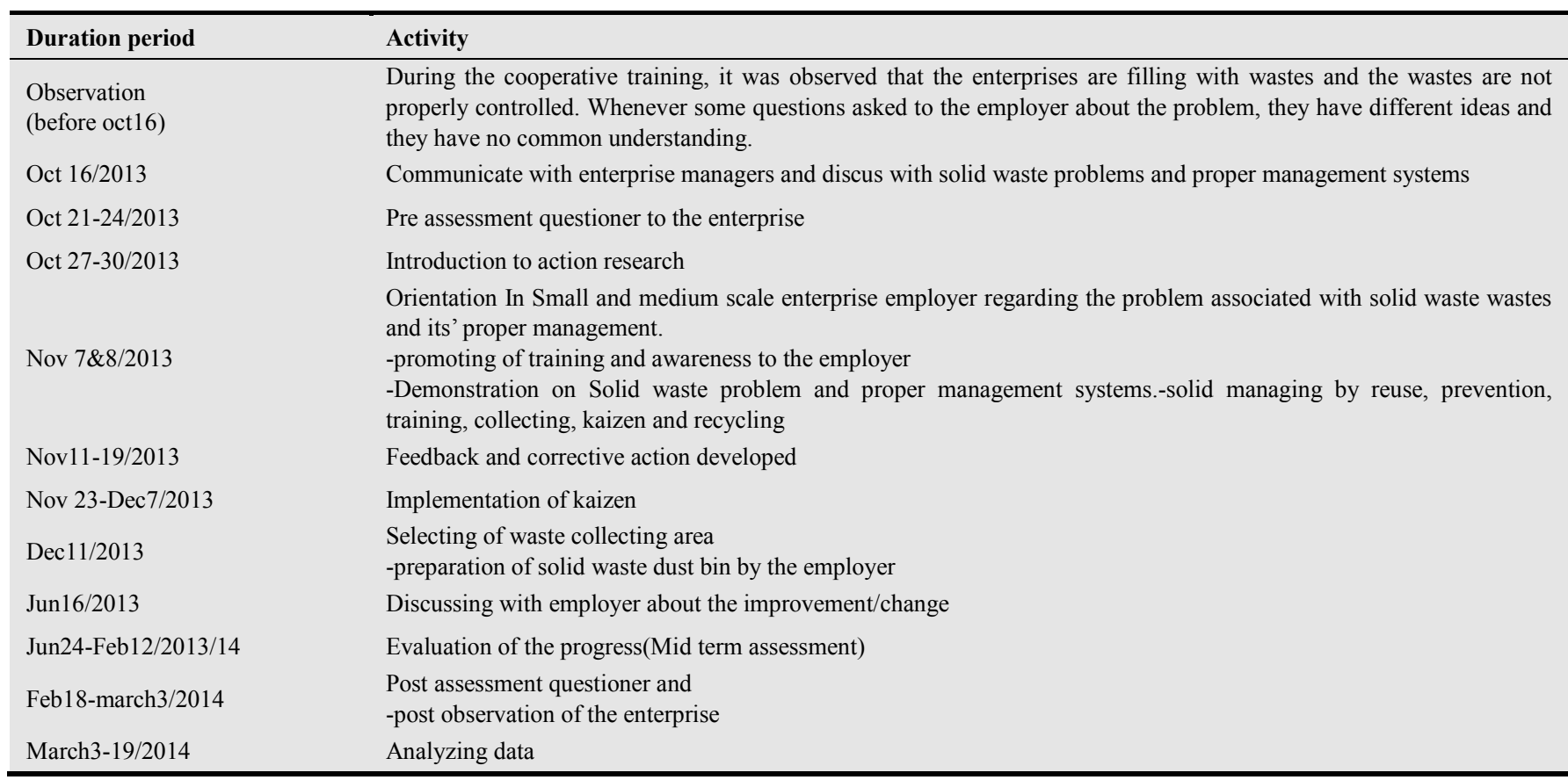

\subsection{Data Presentation}

People said that if you want to change the world, begin from yourself. My intention is, I have develop/crate solid waste management system in In Small and medium scale enterprise. I have started the action in Small and medium scale enterprise and am very hopeful to expand the territory of this work in other enterprises and convey the message of solid waste management in the entrepreneurs.

I organized my data chronologically as I collected it in my file throughout the study. For seven month study can take gate proper solid waste management mechanism within observations and questioner response from the enterprise employer, I feel that more time needs to be spent investigating this solid waste management in order to gate better management systems.

\section{Result and Discussion of the Study}

\subsection{Observation Result}

As the researcher observed and assess at the first period, in the enterprise solid waste management does not know by the employer and wastes are not properly controlled .From observation obtained that awareness and training is a great problem of the enterprise worker for problems of solid waste management systems.

After conducting training for awareness creation, solid waste management problems are slightly changed. Starting of kaizen implementation and capacity building solid waste management is good. For mid and post assessment period the employers use waste collecting facilities, there is know how about waste, use waste collecting facility, isolating of wastes by type and size, some waste materials use as reusing purpose.

\subsection{Interview}

The interviews conducted in the first period of field work revealed employers does not know solid waste management, even they cannot define the term solid waste. In my, interview, this employer described to me, how even though they felt they were not good at using the waste management system; in using technology during production, it consumes our time and many. They told that because of dust bin preparation we spent/lose many.

After crating good awareness, training and kaizen implementation developed in the enterprise. From mid evaluation time obtained that, solid waste management systems are changes in some cases like awareness, reusing, shop cleaning and waste collecting system. On the post assessment time most factors are controlled and the waste management systems is crated the respondent says that this changes are obtained because of awareness, training, implementation and using of kaizen, using waste collecting facility and capacity building of the enterprise. But some factors like recycling are still problems. 


\subsection{From the Questionnaire}

For Meserte Gabi metal and machine work enterprises 10 questionnaires distributed to the enterprise 16 workers. At different time the employer were responded to responds and the response of questionnaires were considered as essential sources for the study.

\subsubsection{First Assessment Time}

This (first) assessment is conduction before training, implementation of kaizen and the result is predicts the problems of solid waste management in the enterprises.

Table 4.1. solid waste management awareness among the employer

\begin{tabular}{llllll}
\hline Activity/task/action & Valid & Frequency & Percent & Valid Percent \\
\hline Do you know waste management? & no & 21 & 100 & 100 & Cumulative Percent \\
\hline
\end{tabular}

From the above table it is seen that $100 \%$ of employer don't know Solid waste management practice they have been practicing is sustainable or not. So there is a great need of solid waste management awareness among the employer. Lack of training and poor awareness is the major problems of the enterprises.

Table 4.2. The kind of solid waste activities carry out in the Enterprise

\begin{tabular}{llllll}
\hline Activity/task/action & Valid & Frequency & Percent & Valid Percent & Cumulative Percent \\
\hline & collector & 12 & 57.14 & 57.14 & 57.14 \\
& recycling & 0 & 0 & 0 & 0 \\
What kind of solid waste activities do & Reuse & 2 & 9.52 & 9.52 & 33.33 \\
you carry out? & No action & 7 & 33.33 & 100 & 100 \\
& Total & 21 & 33.33 & 100 \\
\hline
\end{tabular}

Findings: The problems of waste management covers Collecting 57\% Reuse $9.52 \%$, recycling0\%, there no action to control waste is $33.33 \%$. From the result shows that waste were not properly controlled. But there is no improvement in solid waste recycling.

Table 4.3. The type of solid waste material that found and collect in the Enterprise

\begin{tabular}{llllll}
\hline Activity/task/action & Valid & Frequency & Percent & Valid Percent & Cumulative Percent \\
\hline & Mixed & 7 & 33.33 & 33.33 & 33.33 \\
& Wood & 4 & 19.00 & 19.00 & 33.33 \\
What kind of material does your & Metal & 7 & 33.33 & 14.00 & 14.29 \\
firm collect? & Plastic & 3 & 100 & 100 & 14.29 \\
\hline
\end{tabular}

From the above table it is seen that about $33.33 \%$ Mixed waste is collected in the enterprises. But below $23 \%$ waste is collected by there type. For proper waste management system, it collects by their type and size, otherwise the mechanism is poor. Hence from the result shows that small amount of wastes are collect by their type, then this small amount isolation is an indication of problems of solid waste management.

Table 4.4. The effect of conducting training and capacity building for solid waste management

\begin{tabular}{lllll}
\hline Activity/task/action & Valid & Frequency & Percent & Valid Percent \\
\hline \multirow{2}{*}{ Do you expect that training and capacity } & yes & 5 & 23.81 & 23.81 \\
building is the means of solving SWM & no & 7 & 33.33 & 33.33 \\
problems? & No idea & 9 & 42.86 & 42.86 \\
& Total & 21 & 100 & 33.33 \\
\hline
\end{tabular}

From the above table shows that only $23 \%$ respondents know the importance training and capacity building as means of solid waste management but $33.33 \%$ not agree and $42.84 \%$ of the respondent have not any idea. From the result shows that waste were training and capacity building the main problem of solid waste management in the enterprises.

Table 4.5. kaizen as a Solid waste management

\begin{tabular}{|c|c|c|c|c|c|}
\hline Activity/task/action & Valid & Frequency & Percent & Valid Percent & Cumulative Percent \\
\hline $\begin{array}{l}\text { Do you expect that kaizen is solid } \\
\text { management systems (swm)? }\end{array}$ & No idea & 21 & 100 & 100 & 100 \\
\hline
\end{tabular}


From the above table it is seen that $100 \%$ of employer don't know kaizen as a Solid waste management. So there is a great need of solid waste management awareness among the employer. Lack of training and poor awareness is the major problems of the enterprises.

Table 4.6. Methods of collect solid waste

\begin{tabular}{llllll}
\hline Activity/task/action & Valid & Frequency & Percent & Valid Percent & Cumulative Percent \\
\hline What kind of technology does & Local collector & 16 & 76.19 & 76.19 & 76.19 \\
your firm use to collect the & Employer & 5 & 23.81 & 23.81 & 19 \\
waste? & Total & 21 & 100 & 100 & 100 \\
\hline
\end{tabular}

The table shows that above $76 \%$ waste is collected by waste collector but the employer collect very small amounts about $24 \%$ waste from the total waste. This result shows that waste were not properly controlled for each working time

Table 4.7. The range of solid waste collect and stored in dust bin

\begin{tabular}{|c|c|c|c|c|c|}
\hline Activity/task/action & Valid & Frequency & Percent $\%$ & Valid Percent \% & Cumulative Percent \% \\
\hline \multirow{3}{*}{$\begin{array}{l}\text { Do you think that the waste is properly } \\
\text { collect and stored in dust bin? }\end{array}$} & Yeas & 5 & 23.81 & 23.81 & 23.81 \\
\hline & No & 16 & 76.19 & 76.19 & 76.19 \\
\hline & Total & 21 & 100 & 100 & 100 \\
\hline
\end{tabular}

From table shows that above $76 \%$ waste is not collected and stored within dust bin. The result implies that there are no waste management systems due to shortage of collecting facilities

Table 4.8. Waste Controlling techniques

\begin{tabular}{llllll}
\hline Activity/task/action & Valid & Frequency & Percent & Valid Percent & Cumulative Percent \\
\hline & Reuse & 3 & 14.30 & 14.30 & 14.30 \\
& prevention & 3 & 14.30 & 14.30 & 14.30 \\
How many wastes are controlled per day? & collecting & 4 & 19.00 & 19.00 & 19.00 \\
& No action is done & 14 & 52.38 & 52.38 & 52.38 \\
& Total & 21 & 100 & 100 & 100 \\
\hline
\end{tabular}

The problems of waste management covers above $52 \%$ but from the response obtained that small amount of wastes were Collecting $19 \%$ Reuse $14.30 \%$, recycling $0 \%$ and waste prevention is covers $14.30 \%$. From the result shows that waste were not properly controlled.

Table 4.9. Different solid waste management mechanisms

\begin{tabular}{|c|c|c|c|c|c|}
\hline Activity/task/action & Valid & Frequency & Percent & Valid Percent & Cumulative Percent \\
\hline \multirow{4}{*}{$\begin{array}{l}\text { What do you think the } \\
\text { government should do to make } \\
\text { the solid waste situation in the } \\
\text { enterprise better? }\end{array}$} & Crate recycling industry & 8 & 38.10 & 38.10 & 38.10 \\
\hline & Pay monthly employer & 9 & 42.86 & 42.86 & 42.86 \\
\hline & Training and awareness to the employer & 4 & 19.00 & 19.00 & 19.00 \\
\hline & Total & 21 & 100 & 100 & 100 \\
\hline
\end{tabular}

Different references book and literature explains that training, capacity building and awareness creation of the employer, is the best method of proper solid waste management. But the table shows, for waste controlling systems the responds have different ideas, $38 \%$ respondents told that solve the problem by Crate recycling industry, $42 \%$ Pay monthly employer, training and awareness to the employer is covers $19 \%$.hence the enterprise needs training and capacity building to crate solid waste management mechanisms.

Table 4.10. The enterprise employers moral to implement solid waste management systems

\begin{tabular}{|c|c|c|c|c|c|}
\hline Activity/task/action & Valid & Frequency & Percent & Valid Percent & Cumulative Percent \\
\hline $\begin{array}{l}\text { Will you encourage your worker/employer to give } \\
\text { continuity to this activity? }\end{array}$ & No & 21 & 100 & 100 & 100 \\
\hline
\end{tabular}

The table shows that $100 \%$ respondents did not encourage their worker to crate solid waste management systems. 


\subsubsection{Mid Assessment}

This (mid) assessment is conduction after training, implementation of kaizen and capacity building of the enterprises. The result should predict the problems of solid waste management in the enterprises.

Table. 4.11. The awareness of waste management at Mid Assessment stage

\begin{tabular}{llllll}
\hline & Valid & Frequency & Percent & Valid Percent & Cumulative Percent \\
\cline { 2 - 6 } Activity/task/action & yes & 7 & 33.33 & 33.33 & 33.33 \\
& no & 14 & 66.66 & 66.66 & 66.66 \\
Do you know waste management? & Total & 21 & 100 & 100 & 100 \\
\hline
\end{tabular}

From the above table it is seen that below $33.33 \%$ of the responds know solid waste management but from pre assessment none of them don't know waste management's. Hence due to training and awareness creation there is a considerable positive change in the development of solid waste management.

Table 4.12. The kind and level of solid waste activities carry out in the Enterprise at Mid Assessment stage

\begin{tabular}{llllll}
\hline Activity/task/action & Valid & Frequency & Percent & Valid Percent & Cumulative Percent \\
\hline & collector & 13 & 61.90 & 61.90 & 61.90 \\
& recycling & 0 & 0 & 0 & 0 \\
What kind of solid waste & Reuse & 5 & 23.80 & 23.80 & 14.30 \\
activities do you carry out? & No action & 3 & 14.30 & 100 & 14.30 \\
& Total & 21 & 100 & 100 & 0 \\
\hline
\end{tabular}

The table shows that there is in significance change is seen for waste reduction mechanisms from the first assessment time.

Table 4.13. The level and type of solid waste material that found and collects in the Enterprise at Mid Assessment stage

\begin{tabular}{lllll}
\hline Activity/task/action & Valid & Frequency & Percent & Valid Percent \\
\hline & Mixed & 3 & 14.29 & 14.29 \\
& Wood & 5 & 23.80 & 23.80 \\
What kind of material does your firm & Metal & 10 & 47.62 & 47.62 \\
collect? & Plastic & 3 & 14.29 & 14.29 \\
& Total & 21 & 100 & 100 \\
\hline
\end{tabular}

From the above table it is seen that about $14 \%$ Mixed waste is collected in the enterprises. But above $40 \%$ waste is collected by there type. For proper waste management system, waste collects by there type and size, otherwise the mechanism is poor. Hence from the result shows there was change from the first assessment period that large amount of wastes were collect by there type, then this is an indication of solid waste management mechanism.

Table 4.14. The effect of conducting training and capacity building for solid waste management at Mid Assessment stage

\begin{tabular}{|c|c|c|c|c|c|}
\hline Activity/task/action & Valid & Frequency & Percent & Valid Percent & Cumulative Percent \\
\hline \multirow{4}{*}{$\begin{array}{l}\text { Do you expect that training and capacity } \\
\text { building is the means of solving SWM } \\
\text { problems? }\end{array}$} & yes & 10 & 47.62 & 47.62 & 47.62 \\
\hline & no & 6 & 28.57 & 28.57 & 28.57 \\
\hline & No idea & 5 & 23.80 & 23.80 & 23.80 \\
\hline & Total & 21 & 100 & 100 & 100 \\
\hline
\end{tabular}

From the above table shows that only $48 \%$ respondents know the importance of training and capacity building as means of solid waste management but $28 \%$ not agree and $23 \%$ of the respondent have not any idea. From the result shows that solid waste management mechanism were formed by conducting training and capacity building in the enterprises.

Table 4.15. Effect of kaizen as a Solid waste management at Mid Assessment stage

\begin{tabular}{|c|c|c|c|c|c|}
\hline Activity/task/action & Valid & Frequency & Percent & Valid Percent & Cumulative Percent \\
\hline \multirow{4}{*}{$\begin{array}{l}\text { Do you expect that kaizen } \\
\text { is swm systems? }\end{array}$} & Yeas & 5 & 23.81 & 23.81 & 23.81 \\
\hline & No & 6 & 28.57 & 28.57 & 28.57 \\
\hline & No idea & 10 & 47.62 & 47.62 & 47.62 \\
\hline & Total & 21 & 100 & 100 & 100 \\
\hline
\end{tabular}


From pre assessment $100 \%$ of employer doesn't know kaizen as a Solid waste management. From the above table it is seen that $78 \%$ of employer don't know kaizen as a Solid waste management. So there is a change for the awareness of the employer .hence kaizen is one mechanism for suitable solid waste management systems of the enterprises.

Table 4.16. The level of solid waste collecting Methods at Mid Assessment stage

\begin{tabular}{llllll}
\hline Activity/task/action & Valid & Frequency & Percent & Valid Percent & Cumulative Percent \\
\hline What kind of technology & Local collector & 12 & 57.14 & 57.14 & 57.14 \\
does your firm use to & Employer & 9 & 42.82 & 42.82 & 42.82 \\
collect the waste? & Total & 21 & 100 & 100 & 100 \\
\hline
\end{tabular}

The table shows that above $57 \%$ waste is collected by waste collector but the employer collecting capacity change from $24 \%$ to $43 \%$ waste from the total waste. This result shows that waste were well controlled for each working time. Employer training and encouragement is one mechanism for solid waste management.

Table 4.17. The amount of waste properly collect at Mid Assessment stage

\begin{tabular}{|c|c|c|c|c|c|}
\hline Activity/task/action & Valid & Frequency & Percent & Valid Percent & Cumulative Percent \\
\hline \multirow{3}{*}{$\begin{array}{l}\text { Do you think that the waste is properly collect } \\
\text { and stored in dust bin? }\end{array}$} & Yeas & 8 & 30.10 & 30.10 & 30.10 \\
\hline & No & 13 & 61.90 & 61.90 & 61.90 \\
\hline & Total & 21 & 100 & 100 & 100 \\
\hline
\end{tabular}

From table shows that above $62 \%$ waste is not collected and stored within dust bin. At the first result obtained that $76 \%$ of solid wastes were not properly collected. The result implies that there was management system that developed to control problems of solid wastes.

Table 4.18. The amount of waste manage by different mechanisms at Mid Assessment stage

\begin{tabular}{llllll}
\hline Activity/task/action & Valid & Frequency & Percent & Valid Percent & Cumulative Percent \\
\hline & Reuse & 4 & 19.05 & 19.05 & 19.05 \\
& prevention & 6 & 28.57 & 28.57 & 28.57 \\
How many wastes are controlled per day? & collecting & 7 & 33.33 & 33.33 & 19.05 \\
& No action is done & 4 & 19.05 & 100 & 19.05 \\
& Total & 21 & 100 & 100 & 100 \\
\hline
\end{tabular}

The table shows that solid waste management systems change from Collecting 19\%to 33.33\%, Reuse 14.30\%to19.05\%, recycling $0 \%$ and waste prevention $14.30 \%$ to $28.70 \%$.

Table 4.19. The level of Government responsibility implemented to control waste at Mid Assessment stage

\begin{tabular}{|c|c|c|c|c|c|}
\hline Activity/task/action & Valid & Frequency & Percent & Valid Percent & Cumulative Percent \\
\hline \multirow{4}{*}{$\begin{array}{l}\text { What do you think the government } \\
\text { should do to make the solid waste } \\
\text { situation in the enterprise better? }\end{array}$} & Crate recycling industry & 4 & 19.00 & 19.00 & 19.00 \\
\hline & Pay monthly employer & 9 & 42.86 & 42.86 & 42.86 \\
\hline & Training and awareness to the people & 8 & 38.10 & 38.10 & 38.10 \\
\hline & Total & 21 & 100 & 100 & 100 \\
\hline
\end{tabular}

Different references book and literature explains that training, capacity building and awareness creation of the employer, is the best method of proper solid waste management. The above table shows, for solid waste controlling systems the perspective of the employer is change from the first. Hence 38\% to change 19\% respondents told that solve the problem by Crate recycling industry, from $42 \%$ to $42 \%$ Pay monthly employer, training and awareness to the employer is covers $19 \%$ to $38 \%$. Hence conducting training and capacity building was one method of solid waste management mechanisms.

Table 4.20. The Enterprise worker moral apply Solid waste Management at Mid Assessment stage

\begin{tabular}{|c|c|c|c|c|c|}
\hline Activity/task/action & Valid & Frequency & Percent & Valid Percent & $\begin{array}{l}\text { Cumulative } \\
\text { Percent }\end{array}$ \\
\hline \multirow{3}{*}{$\begin{array}{l}\text { Will you encourage your worker/employer to give } \\
\text { continuity to this activity? }\end{array}$} & Yes & 7 & 33.3 & 33.3 & 33.3 \\
\hline & No & 14 & 66.67 & 66.67 & 66.67 \\
\hline & Total & 21 & 100 & 100 & 100 \\
\hline
\end{tabular}


The table shows that $33.33 \%$ respondents did not encourage there worker to crate solid waste management systems. Because employer encouragement is increase productivity and controls problems within team. Hence from the result shows that employee encouragement is changing from $0 \%$ to $33.33 \%$, for this reason wastes were properly collected and controlled. Then encouragement is one method of solid was management systems.

\subsubsection{Post Assessment}

This (post) assessment is conduction after training, implementation of kaizen and capacity building of the enterprises. The result should predict the problems of solid waste management in the enterprises.

Table 4.21. Solid waste management awareness among the employer at Post Assessment Stage

\begin{tabular}{llllll}
\hline & Valid & Frequency & Percent & Valid Percent & Cumulative Percent \\
\cline { 2 - 6 } Activity/task/action & yes & 16 & 71.20 & 71.20 & 71.20 \\
& no & 5 & 23.80 & 23.80 & 23.80 \\
Do you know waste management? & Total & 21 & 100 & 100 & 100 \\
\hline
\end{tabular}

Table it is shows that above $71 \%$ of the responds knows solid waste management but from pre assessment none of them don't know and at mid assessment covers $33.33 \%$ of solid waste management's. Hence due to training and awareness creation there is a considerable positive change in the development of solid waste management.

Table 4.22. The kind and level of solid waste activities carry out in the Enterprise at post Assessment stage

\begin{tabular}{llllll}
\hline Activity/task/action & Valid & Frequency & Percent & Valid Percent & Cumulative Percent \\
\hline & collector & 15 & 71.42 & 71.42 & 71.42 \\
& recycling & 0 & 0 & 0 & 0 \\
What kind of solid waste management & Reuse & 5 & 23.80 & 23.80 & 23.80 \\
activities do you carry out? & No action & 1 & 4.76 & 4.76 & 4.76 \\
& Total & 21 & 100 & 100 & 100 \\
\hline
\end{tabular}

The table shows that there is in significance change is seen for waste reduction mechanisms from the first assessment time.

Table 4.23. The level and type of solid waste material that found and collects in the Enterprise at post Assessment stage

\begin{tabular}{llllll}
\hline Activity/task/action & Valid & Frequency & Percent & Valid Percent & Cumulative Percent \\
\hline & Mixed & 3 & 14.29 & 14.29 & 14.29 \\
& Wood & 5 & 23.80 & 23.80 & 23.80 \\
What kind of material & Metal & 10 & 47.62 & 47.62 & 47.62 \\
does your firm collect? & Plastic & 3 & 14.29 & 14.29 & 14.29 \\
& Total & 21 & 100 & 100 & 100 \\
\hline
\end{tabular}

From the above table it is shows that about $14 \%$ Mixed waste is collected in the enterprises. But above $40 \%$ waste is collected by their type. For proper waste management system, waste collects by there type and size, otherwise the mechanism is poor. Hence from the result shows there was change from the first assessment period that large amount of wastes were collect by their type, then this is an indication of solid waste management mechanisms in the enterprises.

Table 4.24. The employer knowledge for Training and capacity building is the means of solving SWM problems at post Assessment stage

\begin{tabular}{llllll}
\hline Activity/task/action & Valid & Frequency & Percent & Valid Percent & Cumulative Percent \\
\hline & yes & 16 & 66.66 & 66.66 & 66.66 \\
Do you expect that training and capacity & no & 3 & 14.29 & 14.29 & 14.29 \\
building is the means of solving SWM & No idea & 2 & 9.52 & 9.52 & 9.52 \\
problems? & Total & 21 & 100 & 100 & 100 \\
\hline
\end{tabular}

The above table shows that above $66.66 \%$ respondents know the importance of training and capacity building as means of solid waste management but $14.29 \%$ not agree and $9.52 \%$ of the respondent have not any idea. From the result shows that solid waste management mechanism were formed by conducting training and capacity building in the enterprises. 
Table 4.25. The employer knowledge for kaizen as the means of solving SWM problems at post Assessment stage

\begin{tabular}{llllll}
\hline Activity/task/action & Valid & Frequency & Percent \% & Valid Percent \% & Cumulative Percent \% \\
\hline & Yeas & 15 & 71.43 & 71.43 & 71.43 \\
Do you expect that kaizen is swm & No & 4 & 19.05 & 19.05 & 19.05 \\
systems? & No idea & 3 & 14.29 & 14.29 & 14.29 \\
& Total & 21 & 100 & 100 & 100 \\
\hline
\end{tabular}

From pre assessment $100 \%$ of employer doesn't know kaizen as a Solid waste management. From the mid assessment that $78 \%$ of employer doesn't know kaizen as a Solid waste management and the above table shows that below $15 \%$ of employer don't know kaizen as a Solid waste management. So there is a change for the awareness of the employer .hence kaizen is grate mechanism for suitable solid waste management systems of the enterprises.

Table 4.26. The level of solid waste collecting Methods at post Assessment stage

\begin{tabular}{llllll}
\hline Activity/task/action & Valid & Frequency & Percent & Valid Percent & Cumulative Percent \\
\hline \multirow{2}{*}{ What kind of technology does your } & Local collector & 14 & 66.66 & 66.66 & 66.66 \\
firm use to collect the waste? & Employer & 7 & 33.33 & 33.33 & 33.33 \\
& Total & 21 & 100 & 100 & 100 \\
\hline
\end{tabular}

The table shows that above $66.66 \%$ waste is collected by waste collector but the employer collecting capacity change from $43 \%$ to $33.33 \%$ waste from the total waste. This result shows that waste were not controlled for each working time because of decreasing of employer incentives. Employer training and encouragement is one mechanism for solid waste management.

Table 4.27. The amount of waste collect using dust bin

\begin{tabular}{llllll}
\hline Activity/task/action & Valid & Frequency & Percent & Valid Percent & Cumulative Percent \\
\hline & Yeas & 13 & 61.90 & 61.90 \\
Do you think that the waste is properly & No & 8 & 30.10 & 30.10 \\
collect and stored in dust bin? & Total & 21 & 100 & 30.10 \\
& & 100 & 100 \\
\hline
\end{tabular}

From table shows that below $30 \%$ of solid waste is not collected and stored within dust bin. At the first result obtained that $76 \%$ and second $62 \%$ of solid wastes were not properly collected. The result implies that there was management system that developed to control problems of solid wastes. For proper collecting of solid waste and using waste collecting facility the amount of solid waste management problem is reduced from $76 \%$ to $30 \%$.

Table 4.28. The amount of waste manage daily by different mechanisms

\begin{tabular}{|c|c|c|c|c|c|}
\hline Activity/task/action & Valid & Frequency & Percent & Valid Percent & Cumulative Percent \\
\hline \multirow{5}{*}{$\begin{array}{l}\text { How many wastes are controlled per } \\
\text { day? }\end{array}$} & Reuse & 4 & 19.05 & 19.05 & 19.05 \\
\hline & prevention & 6 & 28.57 & 28.57 & 28.57 \\
\hline & collecting & 9 & 42.86 & 42.86 & 42.86 \\
\hline & No action is done & 2 & 9.52 & 9.52 & 9.52 \\
\hline & Total & 21 & 100 & 100 & 100 \\
\hline
\end{tabular}

The above table shows that solid waste management systems change from Collecting $19 \%$ to $42 \%$, Reuse $14.30 \%$ to $19.05 \%$, and waste prevention $14.30 \%$ to $28.70 \%$. But recycling still problem.

Table 4.29. Governments Responsibility for SWM after the assesment

\begin{tabular}{|c|c|c|c|c|c|}
\hline Activity/task/action & Valid & Frequency & Percent & Valid Percent & Cumulative Percent \\
\hline \multirow{4}{*}{$\begin{array}{l}\text { What do you think the } \\
\text { government should do to make } \\
\text { the solid waste situation in the } \\
\text { enterprise better? }\end{array}$} & Crate recycling industry & 6 & 28.57 & 28.57 & 28.57 \\
\hline & Pay monthly employer & 2 & 9.52 & 9.52 & 9.52 \\
\hline & Training and awareness to the people & 13 & 61.90 & 61.90 & 61.90 \\
\hline & Total & 21 & 100 & 100 & 100 \\
\hline
\end{tabular}

Different references book and literature explains that training, capacity building and awareness creation of the employer, is the best method of proper solid waste management. The above table shows, for solid waste controlling systems the perspective 
of the employer is change from the first. Hence $38 \%$ to change $28 \%$ respondents told that solve the problem by Crate recycling industry, from $42 \%$ to $9.52 \%$ Pay monthly employer, training and awareness to the employer is covers $19 \%$ to $62 \%$. Hence conducting training and capacity building was one method of solid waste management mechanisms.

Table 4.30. Employer moral Apply Waste management after assessment

\begin{tabular}{llllll}
\hline Activity/task/action & Valid & Frequency & Percent & Valid Percent & Cumulative Percent \\
\hline \multirow{2}{*}{$\begin{array}{l}\text { Will you encourage your worker/employer to } \\
\text { give continuity to this activity? }\end{array}$} & Yes & 14 & 66.66 & 66.66 \\
& To & 7 & 33.3 & 33.3 & 36.66 \\
& Total & 21 & 100 & 100 \\
\hline
\end{tabular}

The table shows that $33.33 \%$ respondents did not encourage there worker to crate solid waste management systems. Because employer encouragement is increase productivity and controls problems within team. Hence from the result shows that employee encouragement is changing from $0 \%$ to $66.66 \%$, for this reason wastes were properly collected and controlled. Then encouragement is one method of solid was management systems.

According to the pre- and post-assessment, regardless of how enterprise employer ranked their awareness, comfort and regular use of solid waste management systems in there enterprise, all employer answered that they feel solid waste management system was extremely significant in applying production process and sustainable development.

My findings show a marked difference in the solid waste management systems of the enterprises at different assessment time/period. The difference is obtained due to training capacity building, material utilizations. These differences of pre and post results could be a reflection of the waste management gap in the enterprise. The result shows that from the beginning of the assessment solid waste management system is poor (there are no well defined solid waste management systems). After conducting training, implementation of kaizen the solid waste management system is change, Increase in training and capacity building about solid waste management system the employer was change solid waste management systems. My result show that problems of solid waste management is formed due to the factors like poor material utilization, waste prevention, recycling, resource reuse problems, storage and facility problems, improper waste collecting mechanisms are the common problems of solid waste managements in the enterprises

\subsection{The Result of Observation, Interview and Questioner Data Interpretation and Discussions}

For these response the questionnaire result show that at different assessment period / time ,problems of solid waste management system is different ,before conducting training ,awareness, and capacity building to the enterprise there is no known and visible waste management systems. From the first assessment period the following factors were identified as problems of solid waste management.

\subsubsection{Poor Resource Utilization}

My result show that, Lack of skill man power most of the enterprise produce products wit out any engineering specification (drawings, mock-ups, material requirements of the product, were not available) causing Waste generations in the enterprises.

\section{(i) Waste Storage Problems}

In these enterprises solid wastes, which cannot be accommodated in the normal storage containers and need a special collection mechanism? The waste simply found in the working area and it is reduce production capacity of the enterprises.

\section{(ii) Poor Awareness, Training and Capacity Building}

There is lack of awareness, training, and education coupled with the negative attitude and lack of cooperation from government organizations. Therefore, awareness is crucial problem for sustainable solid waste management of the enterprises.

\section{(iii) Waste Prevention}

Waste prevention also called source reduction seeks to prevent waste from being generated. Waste prevention strategies include using less packaging, designing products to last longer, and reusing products and materials. Waste prevention helps reduce handling, treatment, and disposal costs and ultimately reduces the generation of methane. From the analysis observed that the waste prevention of the enterprises are very poor. From the total respondents, 86\% did not consider the Waste Prevention mechanisms due to this the problems controlled only $14 \%$ of the total of solid waste.

\section{(iv) Recycling}

Recycling is a process that involves collecting, reprocessing, and/or recovering certain waste materials (e.g., paint plastic\& glass, metal scraps, concrete waste and plastics) to make new materials or products. Recycling generate many environmental and economic benefits. But the enterprises have not recycling mechanisms of solid waste because of shortage of facility, lack of knowledge and financial problems.

\section{(v) Reuse of Solid Waste}

Waste reuse means to find a new use for components that would be part of the Municipal solid waste, without the need for reprocessing them. These products can be either is reused for their original purpose, or for a different one. Examples of reuse are selling or donating used clothes, using empty glass containers for candy storage, turn empty jars into containers for leftover food, use of refillable pens, among others. But 
the enterprises have little knowledge for reusing of most solid wastes. Only small amount of plastic wastes use for secondary purpose.

\section{(vi) Collection Systems}

The proportion of solid waste generated to that collected is very low in the enterprises. The collection efficiency is also hampered by the inappropriate waste container. The solid waste is not collect properly to control problems of the enterprises production process. The enterprise has not appropriate storage containers to store and collect wastes together.

In general before the action is taken pre assessment result shows that (lack of training, capacity building, implementation of kaizen, poor collecting systems, lack of waste storage facility) the following problems were seen.

- Poor mobilization of resources.

- There are no viable economic incentives to encourage waste recycling, waste reduction to the employer

- Insufficient financial resources for recycling of wastes

- Lack of government and institutional support.

- Poor employer attitudes towards environmental cleanliness shifting responsibility

- Lack of general awareness of solid waste management

- Inadequate solid waste management (SWM) mechanisms at generation points including collection, storage.

- Over-reliance on imported and inappropriate technology and equipments enterprises.

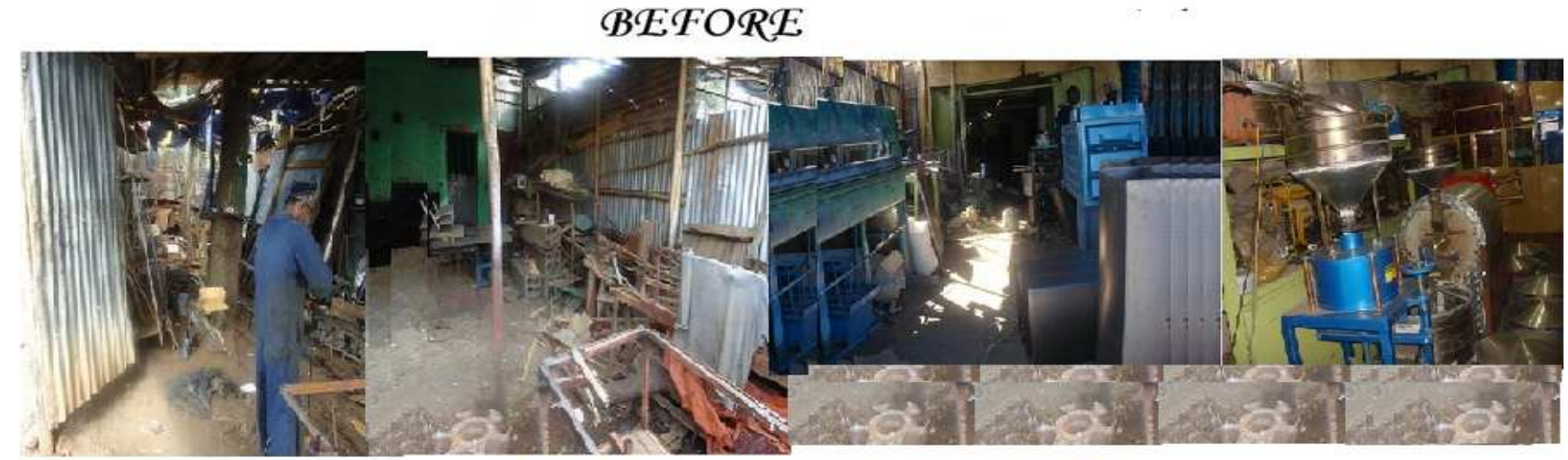

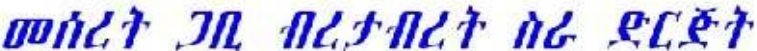

Fig. 4.1. Working area of enterprises before action

\subsubsection{Mid and Post Assessment Result Discussion}

The result shows after conducting of training, implementation of kaizen, visible solid waste management systems are seen in the enterprises and due to developing of solid waste management system through training, kaizen awareness and capacity building, most problems were reduced compare to before but some are still the problem like recycling.

\section{(i) Training Awareness and Capacity Building}

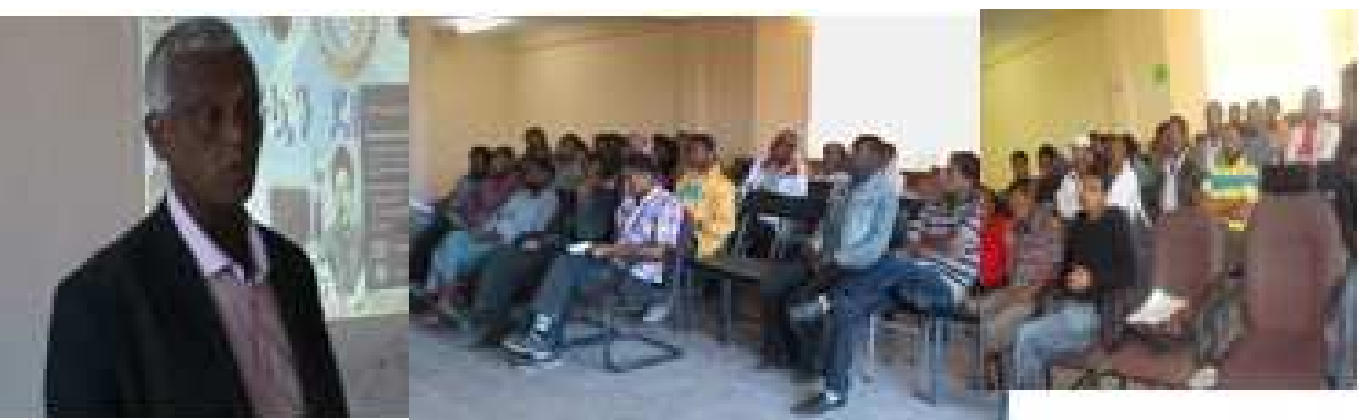

Fig. 4.2. conducting training Capacity building and awareness creation to the enterprises

\section{(ii) Waste Prevention}

Currently, the degree of solid waste management is changed from the first time and before kaizen
The lack of training and educational awareness on solid waste management by major enterprises constraint. Training and capacity building of the enterprises were conducted by trainer. It crate conducive environment to wards good attitude about solid waste management and there is good within the employers in the enterprises. Due to this training and capacity building the waste management system is change from $21 \%$ to56.83 \%. My assessment shows that, Promoting capacity building of enterprises the key actions to crate proper solid waste management of the enterprises. 
So as to reduce the amount of waste $14 \%$ from before action and increase solid waste prevention capacity from $14 \%$ to $24 \%$.hence implementing of kaizen is one mechanism for solid waste management in the enterprises.

\section{(iii) Recycling}

Recycling refers to the removal of items from the waste stream to be used as raw materials in the manufacture of new products. But In the enterprises Recycling is not done because of the cost of system is difficult by the enterprises but collecting the recyclable material and to sell local collectors. Still this is the major problems.

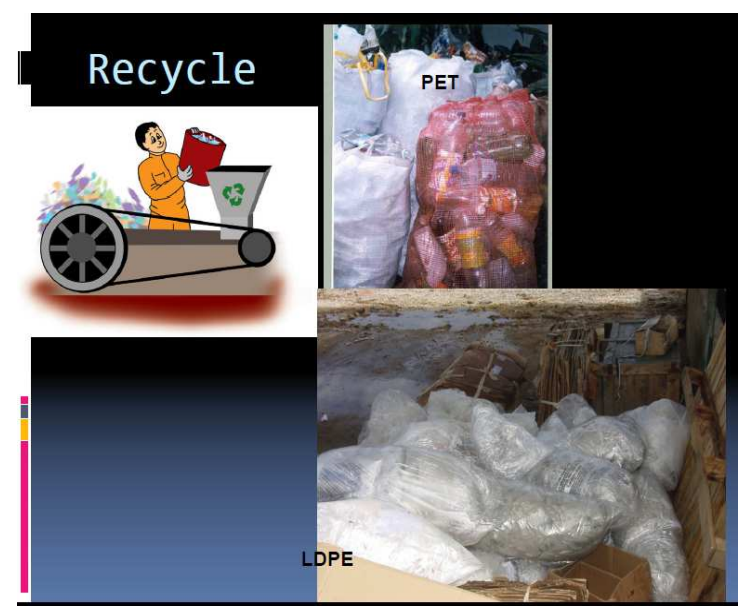

Fig. 4.3. Recycling

\section{(iv) Reused}

My result shows, for conducting training and capacity building increase the awkwardness of reuse of materials, because of these waste management system is are changed from the previous to this time. The Reuse of products is beast methods of solid waste prevention. They encouraging the customers to choose reusable products they eliminate the production of waste at the source of usual generation and reduce the demands for large scale treatment and disposal facilities. The enterprise to regulate the types and amount of packaging used by manufacturers and make the reuse of materials the capacity increase from 9.52 to $21 \%$.

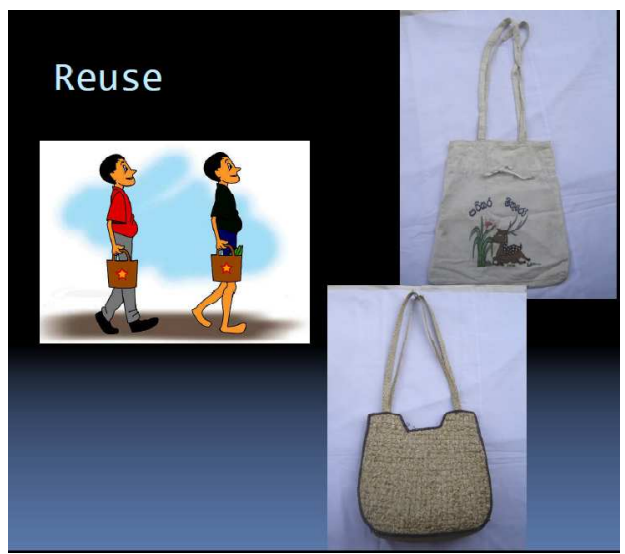

Fig. 4.4. Reused

\section{(v) Storage Facilities/Storage Containers}

After proper training and capacity building the enterprises prepare dust bin for cost collect facility. The perspective of enterprises is change for waste collection system and they used the containers to collect waste. The storing facility changes from $23 . \%$ to $62 \%$.proper solid waste storage facility is on mechanism for proper solid waste management systems.

\section{(vi) Collection Systems}

The Enterprises increase waste profile, so as to promote a general understanding of the significance of proper waste collecting mechanism. It is also possible that collect the waste by there type and size for manageable condition, Allows the use of same collection equipment as usual, they Improved waste collecting mechanisms.

- Preparing and designing of the waste collection sites

- Solid Wastes should be put in place

- There should apply daily and weekly schedule for shop cleaning and collection of wastes. The process improves from $21 \%$ to $51 \%$. Hence proper solid waste storage facility is other mechanism for proper solid waste management systems.

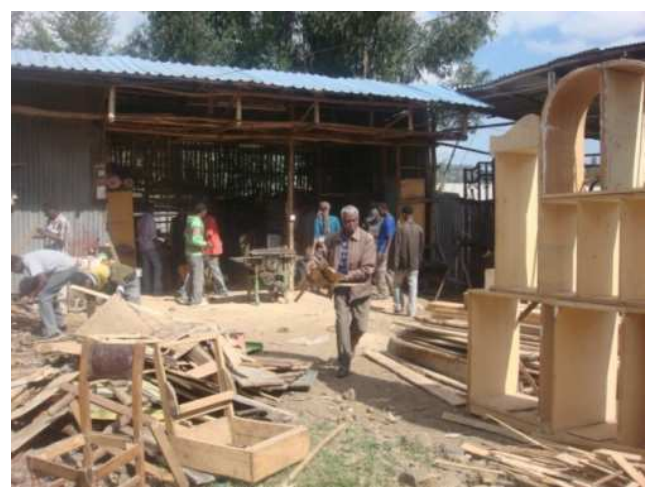

Fig. 4.5. waste collecting during kaizen

In general after the action is taken (conducting training, capacity building, and implementation of kaizen, proper collecting systems, and waste storage facility) the following results are obtained

- Increase the capacity of the solid waste management in the enterprises.

- Separation of waste at source to reduce the amount disposed at the dumpsite

- Redesigning of the waste collection sites i.e. the transfer stations to be user friendly.

- There should be daily and a weekly schedule for collection of wastes

- Improve enterprise waste collection and disposal authority

- Reuse some wastes properly

- To identify the problems of solid waste management in the enterprises.

- The enterprises acquire knowledge about waste management systems.

- Insufficient financial resources for recycling of wastes 
(still problem)

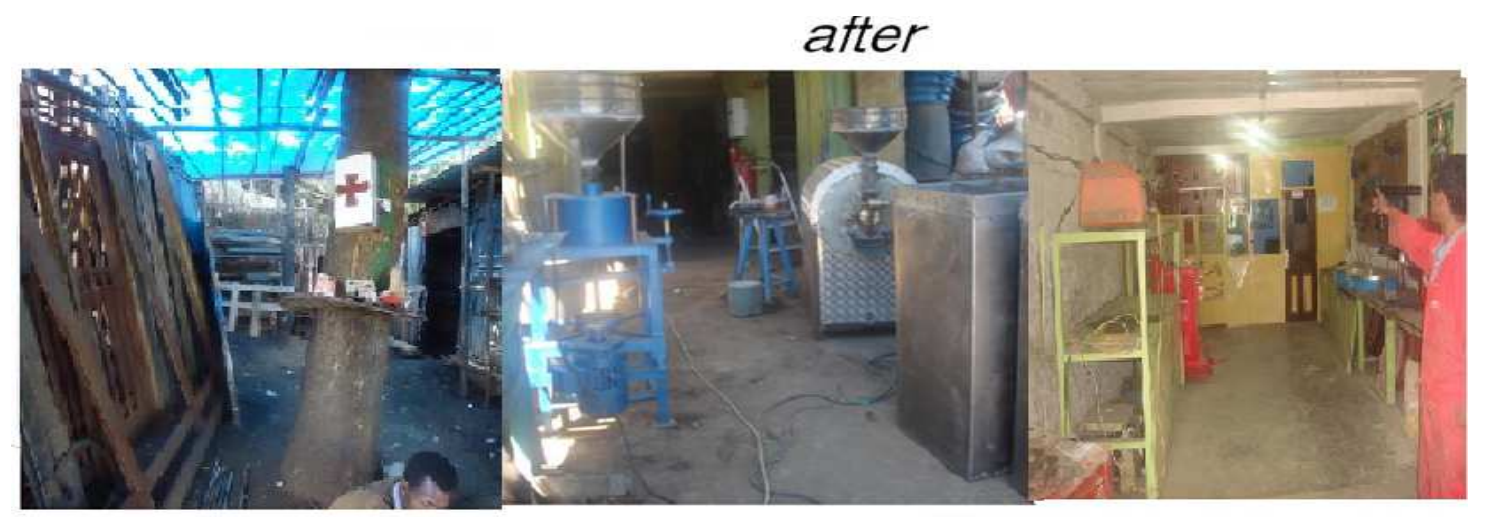

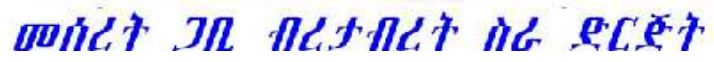

Fig. 4.6. Working area of enterprises after action

\subsection{Comparisons of Solid Waste Management before to After Action}

Table.4.31. The results of waste problems and improvements

\begin{tabular}{|c|c|c|c|c|}
\hline Factor & Pre assessment/before action in $\%$ & $\begin{array}{l}\text { Mid assessment } \\
\text { (during Action) in\% }\end{array}$ & $\begin{array}{l}\text { Post assessment } \\
\text { (after action)in \% }\end{array}$ & $\begin{array}{l}\text { Improvement/change } \\
\text { in } \%\end{array}$ \\
\hline Prevention & 14 & 28 & 28 & 14 \\
\hline Reuse & 11.76 & 21 & 21 & 10.34 \\
\hline Collecting & 21 & 45 & 51 & 30 \\
\hline Storage facility & 23 & 30 & 62 & 39 \\
\hline Recycling & 0 & 0 & 0 & 0 \\
\hline Trainings & 21 & 47 & 63 & 42 \\
\hline Kaizen & 0 & 23.81 & 71.43 & 71.43 \\
\hline Cumulative & & & & 29.54 \\
\hline
\end{tabular}

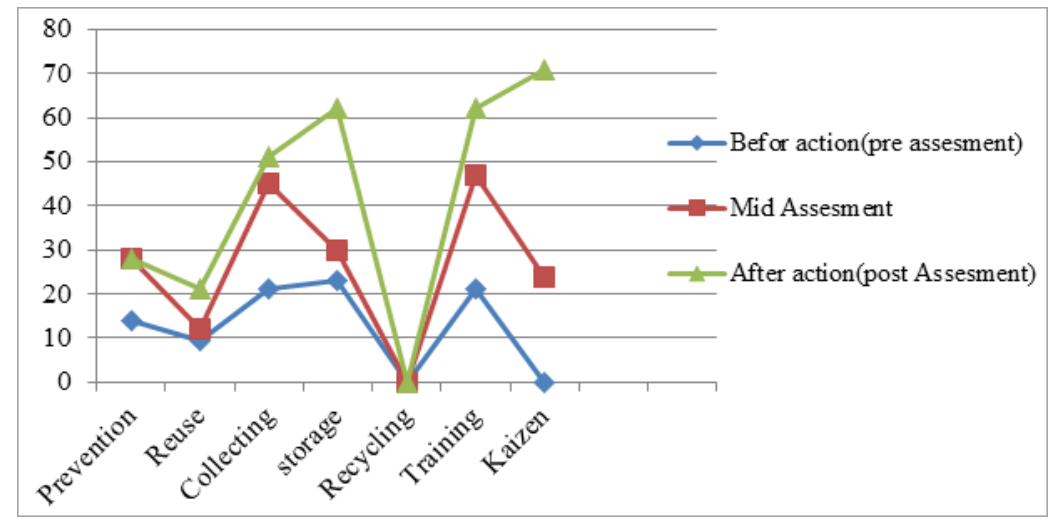

Fig. 4.7. Line chart t analysis

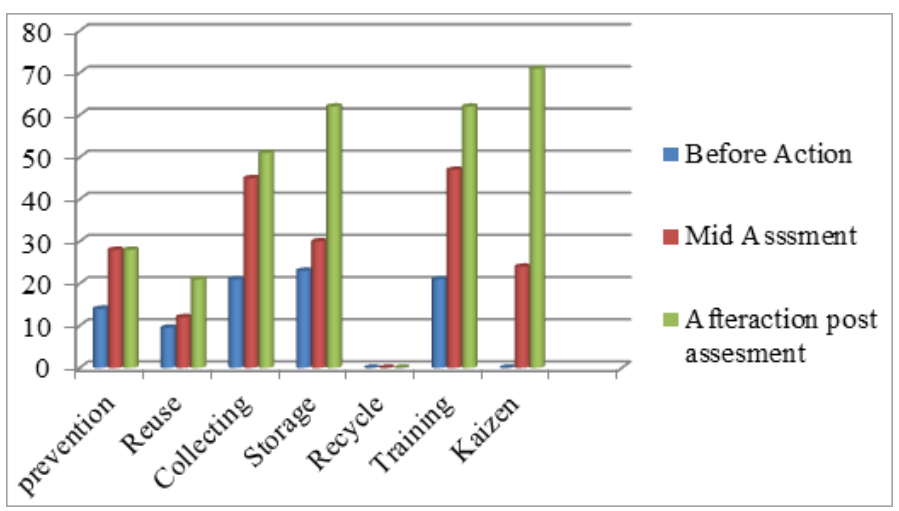

Fig. 4.8. Pareto chart t analysis 


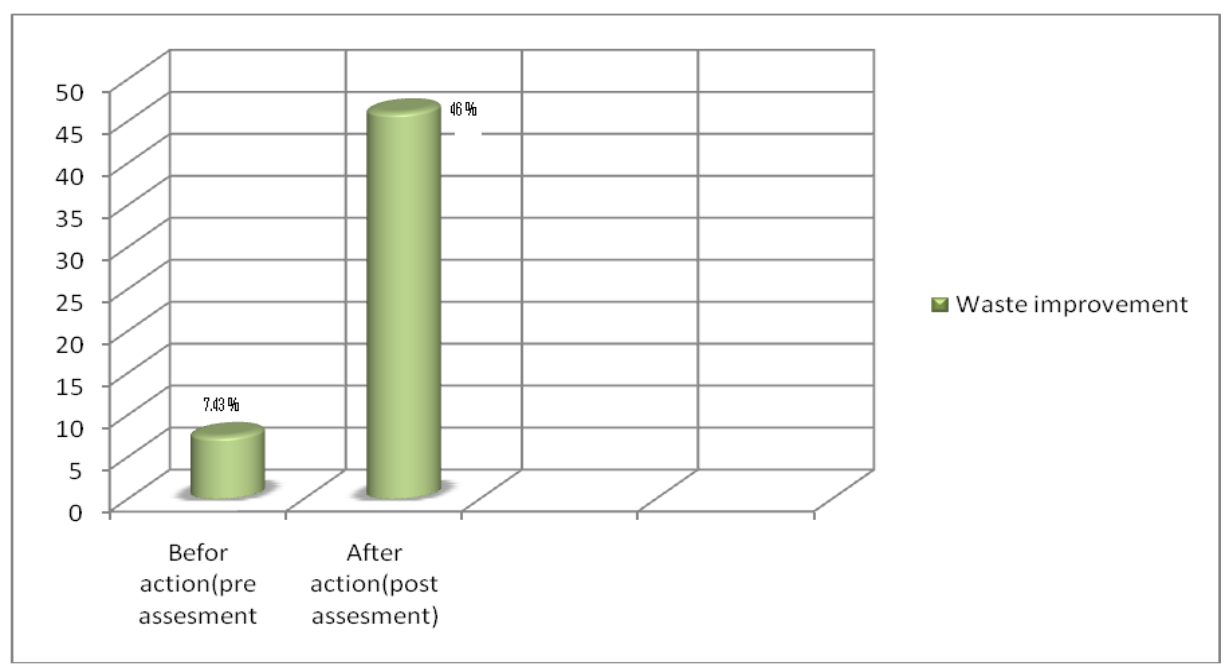

Fig. 4.9. Problems of Waste management system improvement

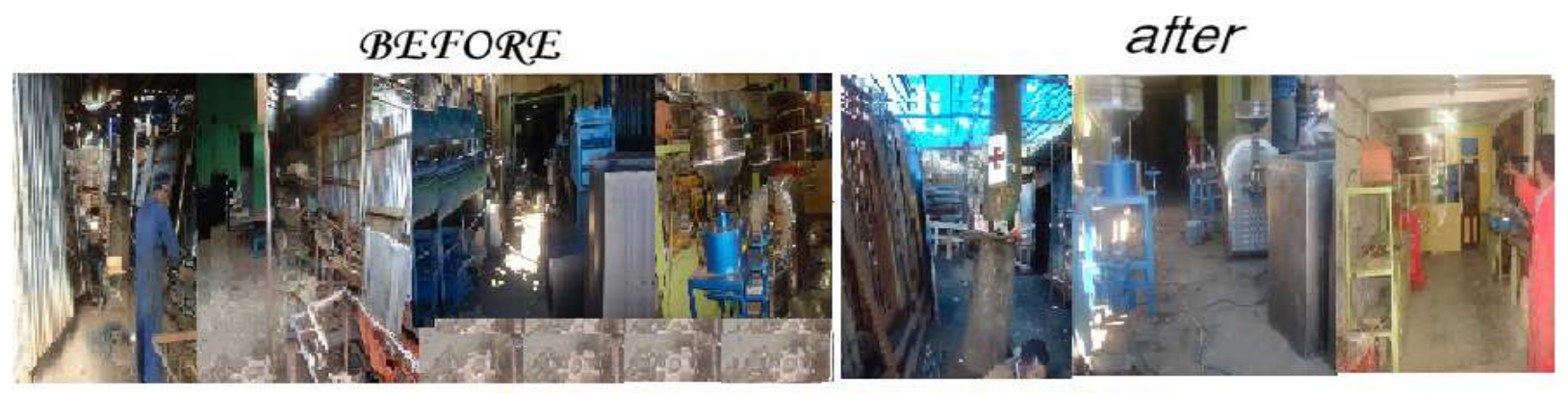

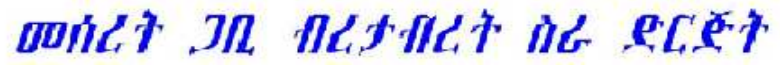

Fig. 4.10. Working area of the enterprise's before and after action

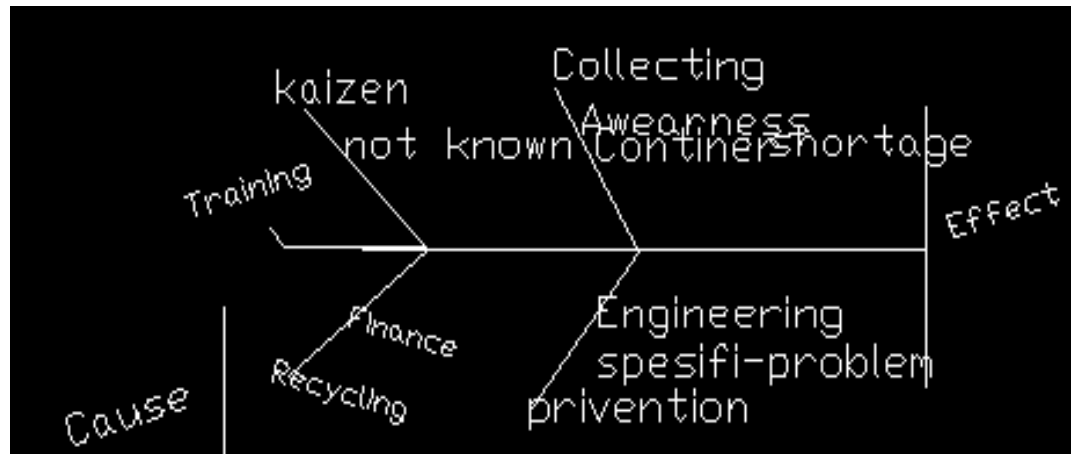

Fig 4. 11.a) Fish bone) cause and effect diagram to see effects of Solid waste( before action)

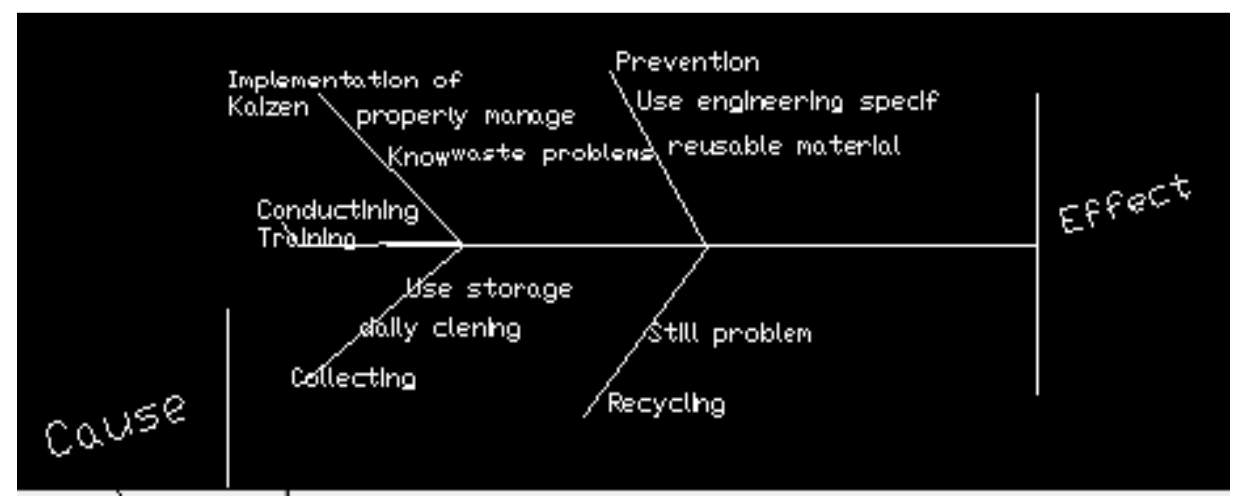

Fig 4. 11b). Fish bone (cause and effect) diagram to develop of Solid waste management (after action) 


\section{Summary}

The aim of this research of problems of solid waste management was, to provide an efficient and sustainable solid waste management system and improving productivity of the enterprise through the development of solid waste management systems within participation stockholders. The conducted literature review revealed that, although similar studies were conducted in the previous the developed models were unable to consider simultaneously all the parameters influencing solid waste management this research were conducted using purposive sampling technique with sample size of one enterprise 1 manager and 15 workers, with total of 16 employers included in the study.

The study were used for analysis the problems of solid waste management's and actions taken to developed solid waste management systems in the enterprises. In the study using filed observation, unstructured interviews and questioners the research of problems of solid waste management of enterprises were conducted. The research was prepared as pre and post (after actions) analysis. The result shows that Solid waste management was characterize major problems of these enterprises. For assessing of the problem of solid waste management in Meserte Gabi metal and Machine work, the following findings were obtained like improper waste prevention, reusing, recycling, collecting, lack of training and awareness are the major problems.

Besides to reduce the problems we apply conduction training, capacity building to the enterprises and implementation of kaizen, solid waste management system were developed and there were positive change was seen in this enterprises. The result also shows that after these actions were taken the enterprise could adopt solid waste management systems and they reduce the amount of wastes in the following way. Achieving sustainable development of the enterprises, Improvement of waste prevention is increase from $14 \%$ to $28 \%$. Reuse of products is beast methods of waste prevention. Reuse of materials the capacity increase from 19.52 to $21 \%$.on the other hand before and after action is done recycling is the major problems. There is no any recycling organizations are crated around Dessise. The enterprises use waste to collect and store wastes, the facility improves from $23 \%$ to $62 \%$ and Collection of solid wastes is the most impact of waste management and using collection system the enterprises can increase the amount of waste from $21 \%$ to $51 \%$.

From the conducting questionnaires, interviews, and observation found that the production of the enterprise in the work shop were not consider the important factors of proper solid waste management's, however the researcher shown and considered important actions were done to develop proper solid waste systems in the enterprises. Hence from the action conducting training, capacity building, resource utilization, and implementation of kaizen were mechanisms that developed solid management systems in the enterprises.

\section{Conclusion and Recommendation}

\subsection{Conclusion}

The problems of solid waste management result shows that Solid waste issues characterize major problems of Meserte Gabi metal and machine work enterprise. For assessing of the problem of solid waste management in the enterprises for, the following findings are obtained like waste prevention, reusing, recycling, collecting, storage facility and training and awareness are the major problems. The result also shows that after the action is taken (by conducting training, resources utilization, capacity building and implementation of kaizen) the enterprise should adopt solid waste management systems and they reduce the amount of wastes in the following way.

- Waste Prevention

Achieving sustainable development of the enterprises, Improvement of waste prevention is increase from $14 \%$ to $28 \%$.

- Reuse

Reuse of products is beast methods of waste prevention. Reuse of materials the capacity increase from 19.52 to $21 \%$.

- Recycling

Before and after action is done recycling is the major problems. There is no any recycling organizations are crated around Dessise.

- Storage facilities/ Storage Containers

The enterprises use waste to collect and store wastes, the facility improves from $23 \%$ to $62 \%$

- Collection Systems

Collection of solid wastes is the most impact of waste management and using collection system the enterprises can increase the amount of waste from $21 \%$ to $51 \%$

Hence designing of solid waste management action research enterprise level through conducting training, capacity building, resource utilization, and implementation of kaizen were mechanisms that developed solid management systems in the enterprises, will help to enhance the solid waste reduction and improve productivity of the enterprises.

\subsection{Recommendations for Action}

The findings of this study have important implications for interventions designed to enhance problems of Solid waste management in Meserte Gabi metal and Machine work enterprise i.e small and medium scale enterprise in Dessise and in similar sister enterprises and cities with in Ethiopia. Hence, policy makers and stakeholders could promote and facilitate the growth of small enterprises by accessing necessary infrastructural facilities.

Finally a number of concrete recommendations are done to improve the effectiveness of the enterprises solid waste management was proposed, covering the following areas.

Action From the enterprise

- Increase the amount of waste containers (in side and 
outside the work shop).

- Encourage the employer by giving incentives

- Conduct workshops for stakeholders

- The enterprises should consider training the workers to upgrade their skills.

- Conduct continuous Trainings on solid and waste management technologies

Action from government

- Increase the enterprises awareness, education and participation in the waste management program.

- Conduct continuous Trainings on solid and waste management technologies

- Promote/crate recycling departments in educational institutions.

- The government/town and urban administrator) should design the waste collection sites of the enterprises.

\section{Acknowledgements}

I would like to thanks Dr. Tafesse G/Senbet for giving the necessary documents and helpful guidance, for accomplishment of this research work. Next the author thanks very much for all my Paper Reviewers detail and wonderful reviewing and amazing feedback of the paper to increases scientific acceptance and strength of the paper. The authors also wish to thank the support from the sciencepublishinggroup.com/j/ijema under grants ISSN: 2328-7659 (Print); ISSN: 2328-7667 (Online).

\section{References}

[1] Seadon (2006) Integrated Waste Management- Looking Beyond The Solid Waste Horizon.

[2] Ferguson, (1995). Managing and Minimizing Construction Waste, London.

[3] Yuping, (2003) Development Of The Nanshan Culture Tourism Zone In Hainan, China:

[4] Di Vita (2004). Renewable Resources and Waste Recycling. Environmental Modelling And Assessment
[5] Jones (2007).Environmental And Health Challenges of Municipal Solid Waste in China. China Environment Forum

[6] Flowerdew, Martin (2005). Methods in Human Geography: A Guide for Students Doing A Research Paper. Second Edition. Pearson Prentice Hall England.

[7] Forsyth, (2005). Enhancing Climate Technology Transfer through Greater Public-Private Cooperation: Lessons from Thailand and the Philippines.

[8] Furedy, (2002).Urban Waste and Rural Farmers: Enabling Low- Cost Organic Waste Reuse In Developing Countries. Retrieved August 2007, From City Farmers Website:

[9] (2004). International Solid Waste Association \& United Nations Environment Program (ISWA \& UNEP)

[10] By Solomon Worku Agaje July 2004 ,Socio Economic Determinants Of Growth Of Small Manufacturing Enterprises In Addis Ababa, Addis Ababa University School Of Graduate Studies

[11] By Camilla Louise Bjerkli Julu 2005 The Cycle Of Plastic Waste: An Analysis On The Informal Plastic Recovery System In Addis Ababa, Ethiopia, Norwegian University Of Science And Technology Depart

[12] Vivian W. Y. Tam(2009) Waste Management Parameters For Assessing Recycled Aggregate And Their Correlation Griffith School Of Engineering, Griffith University, Gold Coast, Queensland, Australia

[13] Juan Wary 2011Industry Extension Program No005/2003E.C Addis Ababa

[14] Christian Zurbrügg (2003) Urban Solid Waste Management In Low-Income Countries Of Asia How To Cope With The Garbage Crisis, Swiss Federal Institute For Environmental Science And Technology (EAWAG)

[15] By Dr Kalpana Sankar (2004),Environmental Protection That Benefits The Poor

[16] Prof. R. Rameezdeen (June 2010), Sustainability In Built Environment

[17] Gloria Elizabeth Ichim(2007),Assessing The Challenges And Potential Of Implementing Composting As Part Of A Municipal Solid Waste Management System, In Baisha, 